\title{
Risk factors for drug resistant bacterial infections: Hospital based study
}

\author{
Habip GEDIK \\ Department of Infectious Diseases and Clinical Microbiology, Ministry of Health Okmeydani Training and Research \\ Hospital, Istanbul, Turkey. \\ Accepted 9 December, 2011
}

\begin{abstract}
The aim of this study is to assess the possible risk factors of patients from whom were isolated microorganisms which were resistant to broad spectrum antibiotics so as to shed light on the measures that should be taken in hospitals and community. These patients were those admitted to Çan secondary care hospital between January, 2009 and November, 2010. The strains isolated from them were evaluated and compared with respect to extended spectrum beta lactamases (ESBL)-producing gram negative bacteria, MRSA and Enterococcus spp. A total of 289 patients and their 338 isolated strains were included in the study. The patients with 72 ESBL- producing gram negative bacteria were compared with the patients with 224 non-ESBL-producing gram negative bacteria, and five patients with MRSA were compared with 19 patients with MSSA. The patients treated with vancomycin which is sensitive 18 Enterococcus spp. strains were evaluated descriptively. Hospitalization in the previous three months, underlying conditions, and usage of quinolones were found to be significant risk factors for infections with ESBL-producing organisms. Urinary system disorders or malformations, chronic renal failure and hospitalization in the previous three months were found to be risk factors for MRSA infection. It is most likely that hospitalization and underlying conditions contribute to the spread and increase of antimicrobial resistance rates at community and hospitals.
\end{abstract}

Key words: Drug resistance, antimicrobial, risk factor, community-acquired infections, extended spectrum beta lactamases (ESBL), methicillin-resistance for S.aureus (MRSA).

\section{INTRODUCTION}

Antimicrobial resistance has been on a steady increase worldwide. It was considered as a hospital challenge at first, but many reports and articles have now revealed that it has already invaded the farms, long-term care facilities and communities. Clonal spreading of the bacteria, replicons and transposons are the important steps for development of resistance. Even though antimicrobial resistance occurs by chance, its rate could be neglected as compared to rates related with resistance mechanisms as mentioned earlier. Antimicrobial use increase resistance rates at hospitals and communities thus, leading to selection of resistant bacteria in the flora. Resistant microorganisms related infections prompt the use of broad spectrum antibiotics

\footnotetext{
*Corresponding Author’s E-mall: habipgedik@yahoo.com.
}

and caused the vicious circle between antimicrobial resistance and antimicrobial use (Seppala et al., 1995; Anderson, 2003; Chiew et al., 1998). Many strategies and measures have been presented to reduce the rates of resistant bacteria such as automatic stop orders for use of antibiotics, required pharmacy or infectious disease consultations for prescription of certain antibiotics, surveillance of pathogen-specific resistance rates, and the development of local antimicrobial control policies and guidelines. This problem also contributes to increase health care expenditure (Boyce, 2001; Shlaes et al., 1997; Critchley et al., 2004; Zoutman et al., 2005; Hoban et al., 2011). The aim of this study is to assess the possible risk factors of the patients whose isolated microorganisms were resistant to broad spectrum antibiotics associated with extended spectrum beta lactamases (ESBL's) and methicillin-resistance for S.aureus (MRSA) to shed on light on the measures that 
should be taken in the hospitals and community.

\section{MATERIALS AND METHODS}

\section{Study location and patient population}

This study was conducted in Çan public hospital (ÇPH), a secondary care hospital with 120 beds without intensive care unit. From January, 2009 to November, 2010; the patients who yielded microorganisms with relevant symptoms, fever, increased C reactive protein (CRP) and erythrocyte sedimentation rate (ESR), and had been treated by physicians as being inpatient or outpatient in that hospital, were eligible for inclusion.

\section{Study design and data collection}

Using a retrospective case control study design, the patients with bacterial infections were identified by the presence of a sample that cultivated either Gram-negative or Gram positive bacteria. Patientspecific baseline characteristics including age, gender, history of congestive heart failure (CHF), chronic obstructive pulmonary disease (COPD), diabetes mellitus (DM), chronic liver disease (CLD), underlying conditions and end-stage renal disease requiring dialysis and process of care variables were collected from the automated hospital medical record, microbiology database, and pharmacy database of ÇPH. Data collection was uniform regardless of the initial location of their hospitalization for all patients. Electronic medical records of the inpatients and outpatients which were available for all patients in the automated medical database of $\mathrm{CPH}$ were reviewed to determine prior antibiotic exposure. And also the patients were called to complete their missing data about their antibiotic use, underlying conditions, etc. and to receive their signed consent forms. Patients, who could not be inquired, and had incomplete data and had not signed the consent form, were excluded from this study. Consent form was signed by parents whose children were included to the study.

Blood samples drawn from vein or catheter were inoculated into Bact Alert 3D bottles (bioMérieux Diagnostics, France) and also other samples including urine, sputum, wound, conjunctive, abscess, blood and catheter were inoculated onto $5 \%$ sheep-blood agar (Salubris Inc., Istanbul, Turkey), or chocolate agar (Salubris Inc., Istanbul, Turkey) and MacConkey agar (Salubris Inc., Istanbul, Turkey). Identification, antimicrobial susceptibility and presence of ESBLs were examined by Sensititre system (Trek Diagnostic Systems, Cleveland, OH, USA). The isolated strains, which were defined as asymptomatic bacteriuria or colonisation or contamination by physicians or microbiologists, were excluded from study. Isolated microorganisms did not incubated during hospitalisation. Nosocomial infection rates of the hospital were officially reported as "zero" to National Nosocomial Infection Surveillance Control Center of Turkey in 2009 and 2010 according to Centers for Disease Control (CDC) surveillance definition criteria for health care-associated and specific types of infections of the acute care settings. Microorganisms which were acquired during health care of an outpatient, were evaluated with the others due to the fact that they could not be discriminated exactly.

\section{Definitions}

All definitions were selected before initiation of the study. Patients were classified as yielding ESBLs producing Gram negative bacteria, non-ESBL producing bacteria, and Gram positive bacteria divided into methicillin resistance and methicillin sensitive for $S$. aureus and Enterococcus spp. strains. Antimicrobial exposure was defined as taking at least one daily dose of those antibiotics including ceftriaxone, cefixim, amoxycillin-clavulanate, quinolones (ciprofloxacin, levofloxacin, moxifloxacin), cefuroxim and amoxycillin within the preceding 90 days. Hospitalization in the previous three months was inquired with underlying conditions and comorbid diseases. Resistance to third generation cephalosporins of any isolated Gram negative bacteria strain was defined as resistance to one of those antibiotics including cefepime, cefotaxime, ceftriaxone, cefixime.

The patients infected with ESBL-producing Gram negative bacteria were compared with the patients with non-ESBL-producing Gram negative bacteria and the patients infected with MRSA were compared with the patients with the patients infected with methicillin sensitive S.aureus (MSSA) for antimicrobial usage in the previous three months, underlying conditions, and hospitalisationin the previous three months. Due to the fact that vancomycin resistant Enterococcus spp.(VRE) was not isolated, isolated vancomycin sensitive Enterococcus spp. strains were evaluated to to reveal the situation of Enterococcal infections in the community.

\section{Statistical analysis}

Statistical analysis was conducted using SPSS, 13.0 (Chicago, IL, USA). Continuous variables were compared by the two-sample $t$ test and dichotomous variables were compared by Pearson $x^{2}$ Received antimicrobial therapy was grouped into antimicrobials to assure adequate cell counts. Logistic regression analysis was conducted to obtain unadjusted odds ratios and revealed as (Odd ratio; 95\% Confidence interval; $p$ value). To determine the risk factors including exposure to antimicrobial agents at last three months, co-morbidity, and hospitalisation in the patients with Gram negative ESBL-producing bacteria and the patients with MRSA were conducted using a logistic regression model, likelihood ratio test. Risk factors that reached statistical significance $(P<0.05)$ using a forward selection process remained in the model. Pearson correlation test was used to test correlation different quantitative variables. $P$ value was always set at 0.05 . Patients who were infected with Gram negative ESBL-producing bacteria were compared with patients who were infected with Gram negative nonESBL-producing bacteria. And also patients who were infected with methicillin resistant $S$. aureus (MRSA) were compared with patients who were infected with methicillin sensitive $S$. aureus (MSSA). Resistance to at least one of $3^{\text {rd }}$ generation cephalosporins was evaluated for only Gram negative microorganisms.

\section{RESULTS}

A total of 289 patients who met the criteria were included in the study with their 338 strains. The $63(25 \%)$ patients infected with $72 \mathrm{ESBL}$ - producing gram negative bacteria were compared with the patients infected with $224(76 \%)$ non-ESBL-producing gram negative bacteria (Table 1), and also five $(20 \%)$ patients infected with MRSA were compared with $19(80 \%)$ patients infected with MSSAin this study (Table 2). Vancomycin sensitive 18 Enterococcus spp. strains that contain 15 (84\%) $E$. faecalis strains from $12(80 \%)$ patients and three (16\%) E. faecium from three (20\%) patients were evaluated descriptively (Table 3). Age distributions and female/male proportions of both ESBL (+) and ESBL (-) groups were similar ( $p: 0.228 ; p: 0.756$, respectively). ESBL producing microorganisms were more isolated from patients who were older than 65 year age (p: 0.001) and younger than first age (p: 0.006), and also from blood (p: 0.007) and 
Table 1. Characteristics and risk factors of patients that had infections with Gram negative bacteria.

\begin{tabular}{|c|c|c|c|}
\hline \multirow{2}{*}{ Variable } & ESBL (+) gram negative strains & ESBL (-) gram negative strain & \multirow[b]{2}{*}{$\mathbf{p}$} \\
\hline & $\mathbf{n}(\%)$ & n (\%) & \\
\hline Patıents & $63(25)$ & $184(75)$ & \\
\hline Female/Male & $36(57) / 27(43)$ & $101(54) / 83(46)$ & 0.756 \\
\hline \multicolumn{4}{|l|}{ Age (year) } \\
\hline Median & 1 & 1 & \\
\hline Range & $0-78$ & $0-77$ & \\
\hline Mean & $22.96 \pm 31.66$ & $14.36 \pm 23.11$ & 0.228 \\
\hline $0-1$ age & $16(22)$ & $86(38)$ & 0.006 \\
\hline $1-5$ age & $17(23)$ & $31(13)$ & 0.102 \\
\hline $5-15$ & $11(16)$ & $24(10)$ & 0.411 \\
\hline $15-65$ & $14(19)$ & $31(13)$ & 0.386 \\
\hline$>65$ & $15(20)$ & $12(5)$ & 0.001 \\
\hline \multicolumn{4}{|l|}{ Underlyıng conditıons } \\
\hline Urinary system malformations or disorders & $9(14)$ & $35(19)$ & 0.396 \\
\hline Chronic obstructive lung disease & $6(9)$ & $14(7)$ & 0.636 \\
\hline Diabetes mellitus & $12(19)$ & $1(0.5)$ & 0.0001 \\
\hline Chronic renal failure & $8(12)$ & $1(0.5)$ & 0.0001 \\
\hline Central venous dialysis catheter & $6(9)$ & $1(0.5)$ & 0.001 \\
\hline Urinary catheter & $13(20)$ & $5(2)$ & 0.0001 \\
\hline Surgical procedure & $7(11)$ & $11(6)$ & 0.127 \\
\hline \multicolumn{4}{|l|}{ Antıbıotıc usage } \\
\hline Cefixim & $45(71)$ & $123(66)$ & 0.363 \\
\hline Ceftriaxon & $33(51)$ & $78(42)$ & 0.144 \\
\hline Amoxycillin-clavulanate & $46(73)$ & $129(70)$ & 0.221 \\
\hline Amoxycillin & $41(65)$ & $127(69)$ & 0.077 \\
\hline Cefuroxim & $15(23)$ & $40(22)$ & 0.710 \\
\hline Quinolones & $12(19)$ & $11(6)$ & 0.004 \\
\hline Hospitalisation & $44(70)$ & $68(37)$ & 0.018 \\
\hline Samples & $72(24)$ & $224(76)$ & \\
\hline Urine & $51(70)$ & $189(85)$ & 0.91 \\
\hline Sputum & $6(8)$ & $7(3)$ & 0.09 \\
\hline Blood & $5(6)$ & $1(0.4)$ & 0.007 \\
\hline Wound & $4(5)$ & $5(2)$ & 0.132 \\
\hline Catheter & $12(16)$ & $1(0.4)$ & 0.0001 \\
\hline Abscess & $1(1)$ & $21(9)$ & 0.03 \\
\hline Mıcroorganısms & $72(24)$ & $224(76)$ & \\
\hline E.coli & $11(15)$ & $122(54)$ & 0.0001 \\
\hline K.pneumoniae & $13(18)$ & $29(12)$ & 0.238 \\
\hline Enterobacter cloacea & $14(19)$ & $17(7)$ & 0.004 \\
\hline Enterobacter sakazakii & $9(12)$ & $1(0.4)$ & 0.0001 \\
\hline Pseudomonas aeruginosa & $1(1)$ & $9(4)$ & 0.157 \\
\hline Enterobacter aerogenes & $4(5)$ & $2(0.8)$ & 0.02 \\
\hline Citrobacter freundii & $10(13)$ & $7(3)$ & 0.405 \\
\hline Morganella morganii & $3(4)$ & $3(1)$ & 0.157 \\
\hline Providencia stuartii & $1(1)$ & $3(1)$ & 1 \\
\hline Acinetobacter baumannii & $4(5)$ & $1(0.4)$ & 0.02 \\
\hline Enterobacter gergoviae & $1(1)$ & $6(2)$ & 0.414 \\
\hline
\end{tabular}


Table 1. Contd.

\begin{tabular}{|c|c|c|c|}
\hline Klebsiella oxytoca & $1(1)$ & $24(10)$ & 0.001 \\
\hline $\begin{array}{l}\text { Resistance to at least one of } 3^{\text {rd }} \text { generation } \\
\text { cephalosporins }\end{array}$ & $19(26)$ & $15(6)$ & 0.001 \\
\hline
\end{tabular}

catheter (p: 0.0001) samples. ESBL production rates were higher in Enterobacter cloacea (p: 0.004), Enterobacter sakazakii ( $\mathrm{p}$ : 0.0001), Acinetobacter baumannii ( $\mathrm{p}: 0.02)$, and Enterobacter aerogenes ( $\mathrm{p}$ : 0.02) strains as compared to other Gram negative bacteria, significantly (Table 1). Urinary catheter $(\mathrm{OR}=$ 9.3; $95 \% \mathrm{Cl} 3.16$ to 27.35 ; p: 0.0001 ), central venous dialysis catheter (CVDC, OR=19.26; $95 \% \mathrm{Cl} 2.27$ to 163.36; p: 0.001), chronic renal failure $(C R F, O R=26.02$; $95 \% \mathrm{Cl} 3.25$ to $217.49 ; \mathrm{p}=0.0001$ ), diabetes mellitus $(\mathrm{DM}, \mathrm{OR}=43 ; 95 \% \mathrm{Cl} 5.46$ to $339.01 ; \mathrm{p}=0.0001$ ) were found significant risk factors as underlying conditions in ESBL (+) group (Table 1). The rates of surgical procedure, COPD, and urinary system malformations or disorders were similar in both groups $(p>0.05)$. Hospitalisation in the previous three months $(\mathrm{OR}=2.6$; $95 \% \mathrm{Cl} 1.16$ to $6 ; \mathrm{p}=0.018)$, underlying conditions (OR = $2.1,95 \% ; \mathrm{Cl} 1.12$ to $7.3 ; \mathrm{p}=0.024)$ and usage of quinolones $(\mathrm{OR}=3.7 ; 95 \% \mathrm{Cl} 1.54$ to $8.88 ; \mathrm{p}=0.004$ ) were found to be significant independent risk factors for infection associated with ESBL-producing organisms. In ESBL (+) group, 12 patients yielded 24 strains related with recurrent infections and six of them had DM, CFR and CVDC and also six of them had COPD. In ESBL (-) group, 27 patients yielded 54 strains regarding with recurrent infections and six of them had urinary system abnormality. There was a significant relation between recurrent infection related with ESBL-producing organisms and underlying conditions $(\mathrm{OR}=0.22,95 \% \mathrm{Cl}$ 0.75 to $0.662 ; p=0.004$ ). Presence of $E S B L$ production was correlated with antimicrobial resitance to those antibiotics including aminoglycosides (amikacin, tobramycin, gentamicin), quinolones (ciprofloxacin, ofloxacin, norfloxacin, levofloxacin), amoxycillinclavulanate, ampicillin-sulbactam, third generation cephalosporins (cefepime, cefotaxime, ceftriaxone, cefixime), second generation cephalosporins (cefoxitin, cefuroxime), piperacillin, trimethoprim-sulfamethoxazole $(p<0.05$; Pearson correlation $r=0.78$ ) excluding piperacillin-tazobactam (TZP, $p>0.05$ ). There was no relationship between resistance to one of third generation cephalosporins and antibiotic use that contains third generation cephalosporins, quinolones, amoxycillinclavulanate, cefuroxim and amoxycillin in the previous three months, but there was a relation between hospitalisation in the previous three months and usage of those antibiotics $(\mathrm{OR}=2.4 ; 95 \% \mathrm{Cl} 0.9$ to $6.3 ; \mathrm{p}=0.04)$. Male/female proportion and age distribution were similar in both MRSA and MSSA groups (p: 0.611). All MRSA strains were isolated from patients who were between 15 to 65 years old (Table 2). Urinary system disorders or malformations $(\mathrm{OR}=12.75 ; 95 \% \mathrm{Cl} 1.26$ to 128.77 ; $\mathrm{p}$ : $0.042)$, chronic renal failure $(\mathrm{OR}=12.75 ; 95 \% \mathrm{Cl} 1.26$ to 128.77; p: 0.042) and hospitalization (OR $=21.33$; $95 \%$ $\mathrm{Cl} 1.72$ to $263.67 ; \mathrm{p}=0.014)$ in the previous three months were found as risk factors for MRSA infection. In Gram positive group, 3 patients yielded 6 strains including four $E$. faecalis from urine samples (Table 3 ). Most of $E$. faecalis strains were isolated from patients who were between 0 to 5 years old. Urinary system disorders or malformations were the most significant risk factor for $E$. faecalis. All E. faecium and most of $E$. faecalis strains were isolated from urine samples (Table 3). All Enterococcus spp. strains were susceptible to vancomycin.

\section{DISCUSSION}

Our findings reveal that ESBL-producing Gram negative bacteria related infections are more likely to be observed in patients with risk factors including those that are older than 65 years of age and younger than one year of age, possessing underlying conditions such as urinary catheter, CVDC, DM, CRF, history of recurrent infections, hospitalization in the preceeding three months and quinolone use in the preceeding three months. Antibiotic should be chosen, taking into consideration this situation in the infected patients with one or more risk factors. Antibiotic should be revised in case of infection with $E$. cloacea, Enterobacter sakazakii, A. baumannii, and $E$. aerogenes species that are more likey to produce ESBLs. Those ages are vulnerable to infections especially Gram negative bacteria infections due to immaturity of organ and systems in in the newborn and infants, for example immunity, and also impaired immunity with underlying conditions such as DM, COPD, congestive heart failure, etc in older ages. Even though, broad spectrum antibiotics use, prolonged hospitalization, invasive procedures, parenteral nutrition, comorbidities, inappropriate surgical procedures, decubitus wounds, hospital flora and fecal carriage were described to predispose to infection with ESBL-producing Gram negative bacteria at hospital, it was seen that those bacteria may be isolated from outpatients with risk factors as presented previously (Schwaber et al., 2004; Colodner et al., 2004). Urinary catheter is an important problem especially in long-term catheterized patients due to colonisation and also becoming a niche for selection of bacteria producing biofilms (Hoban et al., 2011). Patients 
Table 2. Characteristics and risk factors of patients that had infections with MRSA and MSSA.

\begin{tabular}{|c|c|c|c|}
\hline \multirow{2}{*}{ Variable } & MRSA (n:5) & MSSA (n:19) & \multirow{2}{*}{$\mathbf{p}$} \\
\hline & $\mathrm{n}(\%)$ & $\mathrm{n}(\%)$ & \\
\hline Patients & $5(20)$ & $16(80)$ & \\
\hline Female/Male & $3(60) / 2(40)$ & $6(37) / 10(63)$ & 0.611 \\
\hline \multicolumn{4}{|l|}{ Age (year) } \\
\hline Median & 22 & 24 & \\
\hline Range & $18-42$ & $0-66$ & \\
\hline Mean & $29.4 \pm 9.6$ & $21.73 \pm 20.91$ & 0.445 \\
\hline $0-1$ age & - & $3(18)$ & \\
\hline $1-5$ age & - & $2(12)$ & \\
\hline $5-15$ & - & $3(18)$ & \\
\hline $15-65$ & $5(100)$ & $7(43)$ & 0.046 \\
\hline$>65$ & - & $1(6)$ & \\
\hline \multicolumn{4}{|l|}{ Underlying conditions } \\
\hline Urinary system disorders or malformations & $3(60)$ & $2(12)$ & 0.034 \\
\hline Chronic obstructive lung disease & $2(40)$ & $3(18)$ & 0.27 \\
\hline Diabetes mellitus & $2(40)$ & $5(31)$ & 0.608 \\
\hline Chronic renal failure & $3(60)$ & $2(12)$ & 0.034 \\
\hline Central venous dialysis cathater & $1(20)$ & $1(6)$ & 0.564 \\
\hline \multicolumn{4}{|l|}{ Antıbiotic usage } \\
\hline Cefixim & - & & \\
\hline Ceftriaxon & $2(40)$ & $3(18)$ & 0.257 \\
\hline Amoxycillin-clavulanate & $4(80)$ & $12(75)$ & 0.637 \\
\hline Amoxycillin & - & $3(18)$ & \\
\hline Cefuroxim & - & $3(18)$ & \\
\hline Quinolones & $5(100)$ & $14(87)$ & 0.513 \\
\hline Hospitalization & $4(80)$ & $3(18)$ & 0.021 \\
\hline Samples & $5(100)$ & $19(100)$ & \\
\hline Urine & $2(40)$ & $2(10)$ & 0.102 \\
\hline Sputum & - & $1(5)$ & \\
\hline Blood & $1(20)$ & $2(10)$ & 0.564 \\
\hline Wound & $1(20)$ & $5(26)$ & 0.655 \\
\hline Conjunctiva & - & $5(26)$ & \\
\hline Cathater & - & $1(5)$ & \\
\hline Abscess & $1(20)$ & $3(15)$ & 0.325 \\
\hline
\end{tabular}

with DM frequently encounter with redundant antibiotic use in relation to asymptomatic bacteriuria and increased colonisation due to impairment of immunity and local defense system (Daoud et al., 2009). CRF and CVDC predispose to catheter infections related with ESBL producing bacteria as in our study and also with MRSA and non-fermentative Gram negative bacteria causing to impairment of immunity and mucosa and local defense systems, colonisation and biofilm production of bacteria (Kato et al., 2008). Hospitalized patients encounter with higher antimicrobial pressure that increases the selection for resistant strains and the transmission of resistance mechanisms (Moodley et al., 2009; Souza et al., 1999; Yagci et al., 2009) . Subsequent to colonization, patients become harbour for resistant bacteria in the community after discharge. Immunity is a main impaired system due to risk factors as mentioned earlier. The immune response pressurizes the mutant selection window (MSW), contribute to alleviate the negative effects of noncompliance, and influences the optimum dosing strategy. If antibiotic drug concentrations in the blood can be sustained at relatively high levels, the synergistic effect 
Table 3. Characteristics and risk factors of patients that had infections with E. faecalis and E. faecium.

\begin{tabular}{|c|c|c|}
\hline \multirow{2}{*}{ Variable } & E. faecalis(n:15) & E. faecium $(\mathrm{n}: 3)$ \\
\hline & $n(\%)$ & $n(\%)$ \\
\hline Patıents & $12(80)$ & $3(20)$ \\
\hline Female/Male & $7(58) / 5(42)$ & $1(33) / 2(66)$ \\
\hline \multicolumn{3}{|l|}{ Age (year) } \\
\hline Median & 2 & 31 \\
\hline Range & $0-67$ & $0-43$ \\
\hline Mean & $40.12 \pm 26.18$ & $32.09 \pm 4.16$ \\
\hline $0-1$ age & $6(40)$ & $1(33)$ \\
\hline $1-5$ age & $5(33)$ & - \\
\hline $5-15$ & $1(6)$ & - \\
\hline $15-65$ & $2(13)$ & $2(66)$ \\
\hline$>65$ & $1(6)$ & - \\
\hline \multicolumn{3}{|l|}{ Underlyıng conditions } \\
\hline Urinary system disorders or malformations & $6(50)$ & $2(66)$ \\
\hline Chronic obstructive lung disease & $3(25)$ & $1(33)$ \\
\hline Diabetes mellitus & $4(33)$ & - \\
\hline Chronic renal failure & $2(16)$ & $1(33)$ \\
\hline Central venous dialysis cathater & $1(8)$ & - \\
\hline \multicolumn{3}{|l|}{ Antıbıotıc usage } \\
\hline Cefixim & $2(16)$ & $1(33)$ \\
\hline Ceftriaxon & $7(58)$ & $2(66)$ \\
\hline Amoxycillin-clavulanate & $12(100)$ & $2(66)$ \\
\hline Amoxycillin & $3(25)$ & - \\
\hline Cefuroxim & $5(41)$ & - \\
\hline Quinolones & $10(83)$ & $2(66)$ \\
\hline Hospitalization & $3(25)$ & $2(66)$ \\
\hline Samples & $15(100)$ & $3(100)$ \\
\hline Urine & $9(60)$ & $3(100)$ \\
\hline Sputum & $3(20)$ & - \\
\hline Blood & - & - \\
\hline Wound & $1(6)$ & - \\
\hline Conjunctiva & - & - \\
\hline Cathater & - & - \\
\hline Abscess & $2(13)$ & - \\
\hline
\end{tabular}

between immune response and antibiotic in reducing resistance emergence is best for immune response matters that are independent of the dynamics of the bacteria widely (Handel et al., 2008).

Quinolones, which are frequently prescribed for treatment of outpatients' infections such as urinary system infections, exacerbations of COPD, pneumonia, etc due to their broad spectrum, should not be frequently used in treatment of patients with risk factors. Since they contribute to the selection of Gram positive and Gram negative resistant bacteria that can evolve by rapid dissemination of novel resistance genes under selective pressure of antibiotic use. Oral quinolones and amoxycillin-clavulanate are frequently misused antibiotics with by physicians (Hawkey and Jones, 2009). TZP was found significantly sensitive to antibiotic and uncorrelated with ESBL producing bacteria related infections although other beta lactam-beta lactam inhibitor combinations were resistant for ESBL positive strains in our study. It seems that piperacillin-tazobactam could be opted for preventing the development of infection with ESBLproducing organisms. However, piperacillin-tazo-bactam 
was the most commonly administered antibiotic; the clinical cure rate was described as only $55 \%$ in the study of Burgess et al. (2003).MRSA causes to nosocomial infections and also community acquired infections that is prominent in the United States in patients that have risk factors such as DM, immunsuppression, use of quinolones, elderly, young children, as well as urinary system malformations and disorders, hospitalisation and chronic renal failure that were found as risk factors in our study (Tacconelli et al., 2008). Although use of both quinolones and amoxycillin-clavulanate was not found a risk factor for MRSA and MSSA infections, their use rates were very high with least $80 \%$ in our study. E.faecalis was more isolated from patients that were between the ages of 0 and 5 years. Enterococcus spp. strains were isolated from patients with urinary system malformations or disorders and higher antibiotic use rates. Co-morbid conditions predispose to enterococcal infections and also development of resistance to antimicrobials that should in kept mind in choice of antibiotic.

Consequently, it is more likely that hospitalisation and co-morbidity contributes to spreading and increasing antimicrobial resistance at community and hospitals Immunity and infection control program at health care settings are basic factors against development of resistant microorganisms related infections.

\section{ACKNOWLEDGEMENT}

This study was done is Ministry of Health Çan Public Hospital. This study was not financed by any person or firm. Author has no commercial associations that might create a conflict of interest in connection with this article.

\section{REFERENCES}

Anderson DI (2003). Persistence of antibiotic resistant bacteria. Curr. Opin. Microbiol., 6: 452-456.

Boyce JM (2001). Consequences of inaction: importance of infection control practices. Clin. Infect. Dis., 33(3): 133-137.

Burgess DS, Hall II R G, Lewis II JS, Jorgensen JH, Patterson JE (2003). Clinical and Microbiologic Analysis of a Hospital's ExtendedSpectrum Beta-Lactamase-Producing Isolates Over a 2-Year Period. Pharmacotherapy, 23: 10.

Chiew YF, Yeo SF, Hall LM, Livermore DM (1998). Can susceptibility to antimicrobial be restored by halting its use? The case of streptomycin versus Enterobacteriaceae. J. Antimicrob. Chemother., 41: 247-251.

Colodner R, Rock W, Chazan B, Keller N, Guy N, Sakran W, Raz R (2004). Risk factors for the development of extended-spectrum betalactamase-producing bacteria in nonhospitalized patients. Eur. J. Clin. Microbiol. Infect. Dis., 23: 163-167.
Critchley IA, Karlowsky JA (2004). Optimal use of antibiotic resistance surveillance systems. Clin. Microbiol. Infect., 10: 502-511.

Daoud AK, Tayyar MA, Fouda IM, Harfeil NA (2009). Effects of diabetes mellitus vs. in vitro hyperglycemia on select immune cell functions. J. Immunotoxicol., 6(1): 36-41.

Handel A, Margolis E, Levin RB (2008). Exploring the role of the immune response in preventing antibiotic resistance. J. Theor. Biol., 256(4): 655-662

Hawkey PM, Jones AM (2009). The changing epidemiology of resistance. J. Antimicrob. Chemother., 64(1): 3-10.

Hoban DJ, Nicolle LE, Hawser S, Bouchillon S, Badal R (2011). Antimicrobial susceptibility of global inpatient urinary tract isolates of Escherichia coli: Results from the Study for Monitoring Antimicrobial Resistance Trends (SMART) program: 2009-2010. Diagn. Microbiol. Infect. Dis., 70: 507-511.

Kato S, Chmielewski M, Honda H, Pecoits-Filho R, Matsuo S, Yuzawa $Y$ (2008). Aspects of Immune Dysfunction in End-stage Renal Disease. Clin. J. Am. Soc. Neph., 3: 1526-1533.

Moodley A, Guardabassi L (2009). Transmission of IncN plasmids carrying blaCTX-M-1 between commensal Escherichia coli in pigs and farm workers. Antimicrob. Agents. Chemother., 53: 1709-1711.

Schwaber MJ, Cosgrove SE, Gold HS, (2004). Fluoroquinolones protective against cephalosporin resistance in gram-negative nosocomial pathogens. Emerg. Infect. Dis., 10(1): 94-99.

Seppala H, Klaukka T, Lehtonen R, Nenonen E, Huovinen P (1995). Outpatient use of erythromycin: Link to increased erythromycin resistance in group A streptococci. Clin. Infect. Dis., 21: 1378-1385.

Shlaes DM, Gerding DN, John JF Jr, Craig AW, Bornstein DL, Duncan RA, Eckman MR, Farrer EW, Greene WH, Lorian V, Levy S, McGovan JE Jr, Paul SM, Ruskin J, Tenover FC, Watanakunakorn C (1995). Society for Healthcare Epidemiology of America and Infectious Diseases Society of America Joint Committee on the Prevention of Antimicrobial Resistance: guidelines for the prevention of antimicrobial resistance in hospitals. Clin. Infect. Dis., 25: 584-599.

Souza V, Rocha M, Valera A, Eguiarte LE (1999). Genetic structure of natural populations of Escherichia coli in wild hosts on different continents. Appl. Environ. Microbiol., 65: 3373-3375.

Tacconelli E, De Angelis G, Cataldo MA, Pozzi E, Cauda R (2008). Does antibiotic exposure increase the risk of methicillin-resistant Staphylococcus aureus (MRSA) isolation? A systematic review and meta-analysis. J. Antimicrob. Chemother., 61(1): 26-38.

Yagci D, Yoruk F, Azap A, Memikoglu O (2009). Prevalence and risk factors for selection of quinolone resistance Escherichia coli strains in fecal flora of patients receiving quinolone therapy. Antimicrob. Agents. Chemother., 53: 1287-1289.

Zoutman DE, Ford BD (2005). The relationship between hospital infection surveillance and control activities and antibiotic-resistant pathogen rates. Am. J. Infect. Control., 33: 1-5. 